Scientia Agricola

http://dx.doi.org/10.1590/1678-992X-2016-0117

\title{
Carbon losses and soil property changes in ferralic Nitisols from Cuba under different coverages
}

\author{
Alberto Hernández-Jiménez¹, Dania Vargas-Blandino ${ }^{1}$, José Irán Bojórquez-Serrano², Juan Diego García-Paredes² ${ }^{2 *}$ Alberto \\ Madueño-Molina², Marisol Morales-Díaz ${ }^{3}$
}

1National Institute of Agricultural Sciences, P.O. Box 32700
- San José de las Lajas, Mayabeque - Cuba.
Autonomous University of Nayarit/Academic Unit of
Agriculture, km 9 Carretera Tepic - 63000 - Compostela,
Nayarit - Mexico.
3Institute for Fundamental Researches on Tropical
Agriculture, Calles 1 y 2, P.O. Box 17200 - Santiago de las
Vegas, Havana - Cuba.
${ }^{*}$ Corresponding author <digapar@gmail.com>

Edited by: Carlos Eduardo Pellegrino Cerri

Received March 17, 2016

Accepted August 03, 2016
ABSTRACT: The transformation of primary forestlands into lands under cultivation exerts an impact on the physical and chemical properties of the soils, leading to loss of carbon from the soil. The aims of this study were (1) to estimate the impact of different land use on organic carbon stock (OC-stock) and (2) to determine the clay percentage, the dispersion factor, and bulk density with regard to soil management. Thirty soil profiles were sampled as follows: four under primary forests with 80-100 years (old growth); two under secondary wood forests with 45-50 years; eight under secondary young forests with $15-25$ years; four under pasture land with $15-20$ years; and 12 under continuous cultivation for $>50$ years. We determined the changes in $\mathrm{OC}$-stock in the soils under different land-use conditions in relation to the primary forest variant. There was a difference in the $\mathrm{OC}$-stock of the continuous cultivation variant compared to the remaining land-use variants for all soil-thickness layers. The greatest loss of cultivated soil was in the 0-20 cm layer of the primary forest OC-stock. In the 50-100 cm layer, the OC-stock of the cultivated soils diminished significantly. As regards physical properties, such as clay percentage,, dispersion factor, and bulk density, we observed significant differences between the cultivated soils compared to the remaining land-use variants.

Keywords: degradation, carbon reserves, physical properties, tropical soils

\section{Introduction}

The transformation of primary forest land into land under cultivation exerts an impact on the physical and chemical properties of soil, leading to loss of carbon from the soil and its emission into the atmosphere in the form of $\mathrm{CO}_{2}$, which enriches the greenhouse-effect gases that are currently ushering in climate change (Don et al., 2011; Xiong et al., 2014). There are estimates that the conversion of natural ecosystems into agrosystems is responsible for approximately $24 \%$ of worldwide $\mathrm{CO}_{2}$ emissions (IPCC, 2007).

In Cuba, there are extensively weathered tropical forests (Ferralsols, Nitisols, Oxisols, Lixisols, Acrisols, and Alisols). The most extensive area is composed of ferralic Nitisol soil, especially in the western plains (in the provinces of Artemisa, Mayabeque, Matanzas, and Ciego de Ávila), which, because of its profound and friable soil characteristics, has been the main source of food production for the inhabitants of this region.

There are antecedents in the study of red ferralitic soils, and changes in the properties of these soils occur under different forms of land use (Hernández et al., 2013). However, a fresh analysis of these studies produced a classification of the following three general patterns: forests of $>40$ years; forests conserved as pasture land $(\mathrm{PL})$; and forests under permanent cultivation (CU). However, the results presented by Batjes (1996) demonstrate that variation in organic carbon is attributable to its relationship to soil types and their management. For example, Olson (2013), and Olson et al. (2014) mentioned that tillage systems influence soil organic carbon
(SOC) distribution, storage and loss in the surface and subsurface soil horizons. Other factors that affect the dynamics of SOC are land use, climate, and soil landscape processes (Olson et al., 2011, 2012). One essential point to consider is the depth at which soil samples are taken since the interaction between the root system and the soil profile has an influence on soil carbon accumulation (Olson and Al-Kaisi, 2015). Also, organo-mineral interactions are an important factor in SOC storage (Grand and Lavkulich, 2011). Soil texture affects carbon retention capacity, and fine-textured soils usually have more carbon retention capacity than sandy soils (Angers et al., 2011). Based on the latter, the aims of this study were (1) to estimate the impact of different land uses on the organic carbon stock (OC-stock) and (2) to determine the clay percentage, the dispersion factor, and the bulk density together with its implications for soil management.

\section{Materials and Methods}

The study was carried out in the Mayabeque Province, which is located in the western region of Cuba, between $22^{\circ} 34^{\prime}, 23^{\circ} 12^{\prime}$ North Latitude and $82^{\circ} 28^{\prime}$, $81^{\circ} 40^{\prime}$ West Longitude, and is bordered on the west by the Artemisa Province and on the east by the Matanzas Province. This province comprises an area of $3,732.7$ $\mathrm{km}^{2}$ under a sub-humid tropical climate with an annual precipitation of between 1,300 and $1,500 \mathrm{~mm}$, a mean temperature of $24.5^{\circ} \mathrm{C}$, and a plain relief. The material of origin consists of Miocene-age hard limestone.

The soils under study (ferralic Nitisol) form part of the so-called "Red Grasslands of Havana," which cur- 
rently cover the central-southern part of the Mayabeque and Artemisa Provinces, which were created three years ago. For more than two centuries, this area was cultivated, initially with tobacco and later with sugar cane, coffee, and other crops. Its natural formation under forests resulted in fertile soils that are rich in organic matter, which have been reported in other studies as storing a great amount of carbon due to the time factor involved in their formation and to the fact that they are profound and friable soils (Morisada et al., 2003).

These soils have ABtC profiles, a deep red color and are made of clay. Table 1 presents a number of the chemical and physical characteristics of the soils for the $\mathrm{A}$ and Bt horizons for each land use condition. These are soils with high base saturation. The range of $\mathrm{pH}$ values is from slightly acidic (6.70) to slightly alkaline (7.30) in the A horizon. However, in the Bt horizon, the range is from strongly acidic (5.40) to neutral (6.90). Clay is from $69 \%$ in the A horizon to $87 \%$ in the Bt horizon (argillic horizon).

The amount of calcium is predominant with total exchangeable bases from 10.10 to $18.18 \mathrm{cmol}(+) / \mathrm{kg}$ and these soils have high saturation. All of these characteristics demonstrate that the soils are eutric, lixic, and ferralic Nitisols.

In total, 30 ferralic Nitisols soil profiles were studied under five conditions of coverage and land use which were grouped into various categories as follows: four under primary forests $(\mathrm{PF}$ ) 80-100 years old (two of these with ferro-manganese staining at a depth of 70-80 cm); two under secondary wood forests (SF) 45-50 years old; eight under secondary young forests (YF) 15-25 years old; four under pasture lands (PL) 15-20-years old; and 12 lands under continuous cultivation (CU) for > 50 years.

The soils were identified by the World Reference Base for Soil Resources (WRB) classification (International Union of Soil Sciences (IUSS), Working Group, 2014). The soil samples were analyzed at San José de las Lajas, Mayabeque, Cuba, in accordance with the following analytical methods: organic matter according to Walkley \& Black; carbon by dividing the percentage of organic matter by 1.724 ; mechanical composition by the
Bouyoucos method, utilizing sodium pyrophosphate to destroy the microaggregates and sodium hexametaphosphate as dispersant; microaggregate composition by the Bouyoucos method but without chemical reagents; and the dispersion factor (the $\mathrm{k}$ value) by dividing the percentage of clay obtained by mechanical analysis multiplied by 100 .

Bulk density was determined by the cylinder method (100 $\mathrm{cm}^{3}$, volume).

An estimation of the carbon reserves $\left(\mathrm{Mg} \mathrm{ha}^{-1}\right)$ was conducted using the following formula:

$\mathrm{CR}=\mathrm{C}(\%) \times \mathrm{Vd}\left(\mathrm{kg} / \mathrm{dm}^{3}\right) \times$ Layer depth $(\mathrm{cm})$

where: $\mathrm{CR}=$ Carbon reserves; $\mathrm{C}=$ Carbon; and $\mathrm{Vd}=$ Volume density.

The CR were calculated for depths of 0-20, 0-50, and $0-100 \mathrm{~cm}$.

We carried out an analysis of variance (ANOVA) on the results considering a completely random design in which the profiles of each category were considered repetitions and each of the five conditions were considered treatments. We also carried out a means test (Duncan, $0.05)$ to evaluate the significance of the land management over the OC-stock. Additionally, to test whether the data were normally distributed, we ran a ShapiroWilk (W) statistic test. The statistical procedures were conducted using PROC GLM and PROC MEANS in SAS (Statistical Analysis System, version 9.1).

\section{Results and Discussion}

The results demonstrate that the soils in this study, when under permanent coverage, have a content of over $100 \mathrm{Mg} \mathrm{ha}{ }^{-1}$ of organic carbon at a depth of $0-100 \mathrm{~cm}$ (Table 2). The soils under the primary forests (80-100 years old) have a higher OC-stock level (153.25 $\mathrm{Mg} \mathrm{ha}^{-1}$ ), followed by the secondary forests (45-50 years old) with $143.00 \mathrm{Mg} \mathrm{ha}^{-1}$; next, the young forests (15-25 years old) with $124.00 \mathrm{Mg} \mathrm{ha}^{-1}$, and finally the soils under the pasture land accumulate $123.50 \mathrm{Mg} \mathrm{ha}{ }^{-1}$. The forests and pasture land accumulate more organic matter than the

Table 1 - Chemical and physical characteristics of soils for the A and Bt horizon under each land use condition.

\begin{tabular}{|c|c|c|c|c|c|c|c|c|c|c|c|c|}
\hline Land use & Soil horizon (Sh) & Average thickess of Sh & $\mathrm{pH}$ & $\mathrm{OM}$ & Clay & $\mathrm{Ca}$ & $\mathrm{Mg}$ & $\mathrm{Na}$ & K & TEB & EC & BS \\
\hline & & & & & $\%$ & & & & & & $\mathrm{cmol} \mathrm{kg}^{-1}$ & $\%$ \\
\hline \multirow{2}{*}{ PF } & A & 17 & 7.27 & 9.12 & 69.3 & 13.2 & 4.2 & 0.04 & 0.74 & 18.18 & 19.2 & 94.7 \\
\hline & $\mathrm{Bt}$ & 63 & 6.41 & 2.12 & 81.3 & 11.5 & 2.3 & 0.06 & 0.16 & 14.04 & 16.4 & 85.6 \\
\hline \multirow{2}{*}{ SF } & $A$ & 12 & 6.70 & 5.80 & 72.3 & 10.0 & 2.5 & 0.04 & 0.31 & 12.85 & 15.0 & 85.7 \\
\hline & $\mathrm{Bt}$ & 76 & 5.40 & 2.45 & 80.3 & 8.5 & 2.7 & 0.04 & 0.05 & 11.29 & 14.9 & 75.8 \\
\hline \multirow{2}{*}{ YF } & $A$ & 18 & 7.30 & 3.59 & 77.3 & 11.7 & 2.5 & 0.08 & 0.10 & 14.38 & 15.2 & 94.6 \\
\hline & $\mathrm{Bt}$ & 88 & 6.90 & 1.34 & 86.3 & 11.2 & 1.0 & 0.06 & 0.05 & 12.31 & 12.8 & 96.2 \\
\hline \multirow{2}{*}{ PL } & $A$ & 20 & 6.70 & 4.59 & 77.0 & 10.7 & 3.8 & 0.06 & 0.68 & 15.22 & 16.8 & 90.6 \\
\hline & $\mathrm{Bt}$ & 70 & 6.00 & 1.03 & 87.0 & 8.5 & 3.3 & 0.09 & 0.06 & 11.95 & 14.3 & 83.6 \\
\hline \multirow{2}{*}{$\mathrm{CU}$} & $A$ & 20 & 6.90 & 1.51 & 70.0 & 8.6 & 2.8 & 0.10 & 0.73 & 12.23 & 13.2 & 92.7 \\
\hline & $\mathrm{Bt}$ & 78 & 6.50 & 0.45 & 82.3 & 7.5 & 2.3 & 0.10 & 0.30 & 10.10 & 12.5 & 80.8 \\
\hline
\end{tabular}

$\mathrm{PF}=$ Primary forest; $\mathrm{SF}=$ Secondary forest; $\mathrm{YF}=$ Young forest; $\mathrm{PL}=$ Pasture land; $\mathrm{CU}=$ Continuous cultivation; $\mathrm{OM}$ = Organic matter; TEB = Total exchange bases; $\mathrm{EC}=$ Cation exchange; $\mathrm{BS}=$ Base saturation . 
Table 2 - Change in organic carbon stocks (OC-stocks) under Primary forests (PF), Secondary forests (SF), Pasture land (PL), Young forests (YF) and Continuous Cultivation (CU).

\begin{tabular}{|c|c|c|c|c|}
\hline Depth & $\begin{array}{l}\text { Number of } \\
\text { profiles }\end{array}$ & OC-Stocks & $\begin{array}{c}\text { Loss of OC } \\
\text { compared to PF }\end{array}$ & $\begin{array}{l}\text { Type of land } \\
\text { coverage }\end{array}$ \\
\hline \multirow[t]{3}{*}{$\mathrm{cm}$} & & $\mathrm{Mg} \mathrm{ha}^{-1}$ & $\%$ & \\
\hline & 4 & $76.25 \mathrm{a}^{\dagger}$ & - & $\mathrm{PF}$ \\
\hline & 2 & $52.50 \mathrm{~b}$ & 31 & SF \\
\hline \multirow[t]{5}{*}{$0-20$} & 4 & $52.25 b$ & 32 & $P L$ \\
\hline & 8 & $45.63 \mathrm{~b}$ & 40 & $\mathrm{YF}$ \\
\hline & 12 & $28.08 c$ & 63 & $\mathrm{CU}$ \\
\hline & 4 & $112.50 \mathrm{a}$ & - & $\mathrm{PF}$ \\
\hline & 4 & 88.75 a & 19 & $\mathrm{PL}$ \\
\hline \multirow[t]{5}{*}{$0-50$} & 2 & $88.50 \mathrm{a}$ & 21 & SF \\
\hline & 8 & $87.88 \mathrm{a}$ & 22 & YF \\
\hline & 12 & $54.00 \mathrm{~b}$ & 52 & $\mathrm{CU}$ \\
\hline & 2 & $54.50 \mathrm{a}$ & - & SF \\
\hline & 4 & $40.75 a b$ & 25 & PF \\
\hline \multirow[t]{5}{*}{$50-100$} & 8 & $36.13 a b$ & 34 & YF \\
\hline & 4 & $34.50 \mathrm{ab}$ & 37 & $\mathrm{PL}$ \\
\hline & 12 & $22.75 b$ & 58 & $\mathrm{CU}$ \\
\hline & 4 & $153.25 \mathrm{a}$ & - & $\mathrm{PF}$ \\
\hline & 2 & $143.00 \mathrm{a}$ & 7 & YF \\
\hline \multirow[t]{3}{*}{$0-100$} & 8 & $124.00 \mathrm{a}$ & 19 & SF \\
\hline & 4 & $123.25 \mathrm{a}$ & 20 & $\mathrm{PL}$ \\
\hline & 12 & $76.75 b$ & 50 & $\mathrm{CU}$ \\
\hline
\end{tabular}

$\mathrm{PF}=$ Primary forest $\mathrm{SF}=$ Secondary forest $\mathrm{YF}=$ Young forest; $\mathrm{PL}=$ Pasture land; $\mathrm{CU}=$ Continuous cultivation; ${ }^{\dagger}$ Mean values followed by the same letter do not differ between type of land use.

CU soils. Fonseca et al. (2011) found that, in Costa Rican tropical soils under secondary young forests $(\mathrm{YF})$, the soil had an annual growth rate in carbon content of 1.09 $\mathrm{Mg} \mathrm{ha} \mathrm{h}^{-1}$ and that in all of the variants of different forest age, the amount of carbon accumulated in the soil was higher than in the biomass.

The relatively high content in the OC-stock of the soils was in agreement with other results for soils in tropical regions. In Sarawak, Malaysia, Histosols had the greatest amount of organic carbon with 1,100 $\mathrm{t} \mathrm{ha}^{-1} \mathrm{~m}^{-1}$, followed by Oxisols with $200 \mathrm{t} \mathrm{ha}^{-1} \mathrm{~m}^{-1}$ and Ultisols with $160 \mathrm{t} \mathrm{ha}^{-1} \mathrm{~m}^{-1}$, while Entisols had approximately $90 \mathrm{t} \mathrm{ha}^{-1} \mathrm{~m}^{-1}$ and the last, Inceptisols, possessed the least amount, with $60 \mathrm{t} \mathrm{ha}^{-1} \mathrm{~m}^{-1}$. Among the mineral soils, Oxisols store the greatest amount of carbon due to the time-frame for sequestering carbon (Padmanabhan et al., 2013). Other authors report carbon capture numbers in amounts of $>100 \mathrm{Mg} \mathrm{ha}^{-1}$ for ferralitic soils (Oxisols and Ultisols). Batjes (2008) reported a content of $129 \mathrm{Mg}$ $\mathrm{ha}^{-1}$ for Oxisols, and Telles et al. (2003) reported $111 \mathrm{Mg}$ $\mathrm{ha}^{-1}$ for Oxisols in the Amazon. Batlle-Bayer et al. (2010) presented the results from different authors on OC-stock in Latosol soils (ferralitic) from the Cerrado Region in Brazil; the red Latosols, with clay content between 61 and $81 \%$, had an OC-stock of $123-148 \mathrm{Mg} \mathrm{ha}^{-1}$, and the yellow Latosols, with a clay content between 43 and 68 $\%$, had an OC-stock of $185-209 \mathrm{Mg} \mathrm{ha}^{-1}$. In both cases, these values were determined at a depth of 0-100 cm.
Tropical soils are found under stable vegetation many years old (primary forests, secondary forests, or savannahs). They exhibit the capture of carbon that is $>100 \mathrm{Mg} \mathrm{ha}^{-1}$ per meter of profundity; therefore, there are soils that can be very functional in terms of organic carbon sequestration. According to Cheng et al. (2011), soil carbon retention is of great importance because it can potentially compensate for the emissions of fossil fuels of 0.4-1.2 giga-tons of carbon per year.

The same occurs when deep, ferralitic-composition soils are found under $\mathrm{CU}$, which is independent of the carbon capture that is carried out under natural conditions (under PF or SF), that is, the carbon content diminishes, registering the greatest impacts of anthropic action on the upper layer of the profile. In terms of our results, we observed that for the $0-20 \mathrm{~cm}$ soil layer, the OC-stocks manifested more significant values than for any other permanent land use (SF, YF, and $\mathrm{PL})$, ranging between 30 and $40 \%$ for the PF variant, while the greatest significance is found under CU land use (Table 2).

The difference in OC-stock in the CU variant with relation to $\mathrm{PF}$ is $48.167 \mathrm{Mg} \mathrm{ha}^{-1}$, indicating a loss of 63 $\%$ of OC in the soils. This loss in OC-stock that CU soils have undergone compared to those of PF coincides with criteria from other studies. Lal et al. (2007) proposed that in the majority of soils worldwide, carbon loss, due to land-use changes, is found to be between 30 and $75 \%$. Additionally, for tropical soils, in the Hainan Province, China, Deng et al. (2009) found that under sugar cane cultivation over a period of 56 years, the soil lost > $60 \%$ in OC-stock in the soil under the secondary forest.

At a depth of $0-50 \mathrm{~cm}$, there is no marked difference in the changes in OC-stock compared to the PF in relation to the permanent coverages, although the OC-stock tendency is always greater in the PF variant. The statistical analysis conducted shows that there is no significant difference between the PF variant and the remaining permanent coverages (Table 2). This is possibly because, in terms of depth, coverage-change impacts are not evident, such as at a depth of $0-20 \mathrm{~cm}$, and to the fact that the biological activity of $20-50 \mathrm{~cm}$ thickness might be homogeneous for these variants, and thus, the difference would not achieve significance in the OC-stock of the SF, YF, and PL coverages compared to the PF. Olson et al. (2011) compared the storage of SOC on sloping woodland and cropland landscapes of northwestern Illinois, and they found that the woodland landscape had higher SOC in the surface layer than that of the cropland. However, the SOC in the subsurface layers was similar under both land uses.

With respect to the CU variant for more than 50 years, significance was found in the OC-stock content compared to the PF (a loss of $52 \%$ ).

The results for the $0-100 \mathrm{~cm}$ layer also showed the greatest OC-stock for soil under the PF. However, the differences were not significant for permanent coverages. There were significant differences under CU management, which exhibited an OC-stock loss of $50 \%$ compared to soils under the PF. 
In the case of carbon reserves at a depth of 50-100 $\mathrm{cm}$, this registered similar findings, namely, that the greatest loss was in the CU variant. Numerous investigators have demonstrated the impact that soil preparation has in tropical regions on the soil's biological properties in the soil. Tillage mechanically disperses the abiotic and biotic soil-cementing agents; thus, the aggregates and root and mycorrhizoid hyphae fragments are mechanically disaggregated (Beare et al., 2007; Carrizo et al., 2015). The work carried out by the arbuscular mycorrhizal fungal species is important in the formation of soil aggregates through the production of glomalin (Bedini et al., 2009), which is interrupted by soil-preparation work. The impact of land preparation on soil biology is aggravated when herbicides are applied because, the majority of the time, these pesticicides instead of pesticides are toxic to the microorganisms.

The amount of OC-stock at a depth of 50-100 cm under the SF variant reaches higher values than those of the PF, which occurs because out of the four profiles studied in this PF soil, two presented black ferro-manganese staining at a depth of $70-80 \mathrm{~cm}$, which is attributed to symptoms of reduction that diminish the biological activity under $50 \mathrm{~cm}$; thus, the same amount of carbon does not accumulate.

In the CU soil variant, for the $50-100 \mathrm{~cm}$ layer, a considerable part of the carbon is lost $(58 \%)$ in relation to the soil under the SF.

Table 3 depicts the results obtained between landuse type and number of the physical properties, such as the soil's clay content, the amount of clay in the microaggregate analysis, the dispersion factor, and the bulk density.

In terms of clay content, we observed that all of the profiles studied under the different coverages were clay soils, and the most clay was found under the SF, followed by the PL, CU, and YF. The least amount of clay was under the $\mathrm{PF}_{\text {, }}$ and this value was statistically significant compared to the clay under the SF.

In the results obtained for the amount of clay dispersed by different soil-management actions (Table 3), we observed that the CU soil possesses $19 \%$, which is a significant value in comparison to the other land use. The lowest clay level in the microaggregates was found in the PF soils (9\%), with values which are not signifi-

Table 3 - Variation of the physical properties of soils in Primary forests (PF), Secondary forests (SF), Pasture land (PL), Young forests (YF) and Continuous Cultivation (CU).

\begin{tabular}{lcccc}
\hline $\begin{array}{l}\text { Type of land } \\
\text { coverage }\end{array}$ & $\begin{array}{c}\text { Clay in } \\
\text { mechanical analysis }\end{array}$ & $\begin{array}{c}\text { Clay in } \\
\text { microaggregate }\end{array}$ & $\begin{array}{c}\text { Dispersion } \\
\text { factor (k) }\end{array}$ & $\begin{array}{c}\text { Bulk } \\
\text { density }\end{array}$ \\
\cline { 2 - 3 } & $75 \mathrm{a}^{\dagger}$ & $9 \mathrm{~b}$ & $12.55 \mathrm{~b}$ & $1.00 \mathrm{bc}$ \\
$\mathrm{SF}$ & $71 \mathrm{ab}$ & $11 \mathrm{~b}$ & $14.87 \mathrm{~b}$ & $1.07 \mathrm{ab}$ \\
$\mathrm{PL}$ & $68 \mathrm{ab}$ & $19 \mathrm{a}$ & $27.62 \mathrm{a}$ & $1.12 \mathrm{a}$ \\
$\mathrm{CU}$ & $67 \mathrm{ab}$ & $11 \mathrm{~b}$ & $16.02 \mathrm{~b}$ & $1.04 \mathrm{bc}$ \\
$\mathrm{YF}$ & $65 \mathrm{~b}$ & $9 \mathrm{~b}$ & $8.93 \mathrm{c}$ & $0.97 \mathrm{c}$ \\
$\mathrm{PF}$ & \multicolumn{2}{c}{$\%$} \\
tMean values followed by the same letter do not differ between type of land \\
coverage.
\end{tabular}

cant when compared with other coverage types (SF, PL, and $\mathrm{YF}$ ), that are conservation coverages. This might be because in soils under permanent coverage, soil aggregate stability is higher (Hunke et al., 2014).

For ferralitic soils, Cooper et al. (2005) determined that microaggregates are formed from clay, iron, and organic matter. With the loss of the soil's organic matter by cultivation (i.e. carbon), the macroaggregates and part of the microaggregates are fractured, and over time, clay is released from these and is maintained in a dispersed form. Therefore, in the microaggregate analysis, as the land-use changes increase from the soils under the primary forests due to continuous cultivation for many years, the amount of dispersed clay increases. At the same time, changes take place in the soil structure, including changes from a granular to a granular nuciform to a subangular-block structure, presenting very cultivated soils with a plow pan that is sometimes between 15 and $20 \mathrm{~cm}$ in depth.

The relationship between the clay content in the mechanical analysis and that of the microaggregate analysis allows for the determination of the dispersion factor, which, for the same soil, is greater to the extent that there is a greater amount of dispersed clay. This is an important indicator for soils whose composition is ferralitic because it permits the evaluation of the impact of $\mathrm{CU}$ on the transformation of the soil structure and aggregates. This value is tightly related to the stability of the soil's structure.

In the results obtained for the dispersion factor, we also observed a greater value in the CU soils. As regards to this property, there are significant differences for the $\mathrm{CU}$ soils in relation to the other coverage types (PF, SF, YF, and $\mathrm{PL})$. The lowest dispersion value was obtained for the least altered soils, those under the PF, 80-100 years old.

Carbon loss is the result of the loss of the soil's organic matter, which is a fundamental element in soilstructure formation; the amount of organic-matter and its distribution are highly affected by soil management (Beare et al., 2007; Hevia et al., 2007). Green et al. (2007) and Noellmeyer (2008) studied the soils' structural stability in relation to its carbon content and biological activity and determined that soils under traditional cultivation had less OC content, structural stability, and biological activity, due to the action of CU.

One of the most important impacts on the affectation of the physical properties in these soils is the manner in which the clay in the structural aggregates is dispersed, which is the consequence of the aggregate rupture due to human action and land-use changes, which leads to organic matter and also to OC loss in the lands found under more natural conditions as well as in those that are more cultivated. That is, changes in land use and continuous and intensive agricultural exploitation cause the loss of organic matter and organic carbon, which in turn gives rise to the degeneration of their properties and soil productivity (Silva et al., 2010; Hernández et al., 2013). 
With respect to the volume of the soils studied, we observed that when the soils had more dispersed clay and a poorer structure, the soil became denser and less permeable; thus, it is expected that the bulk density would be greater in the soils with less OC and have a higher dispersion value. In this case, we observed the highest bulk density values in the soils under CU, being significant with the $\mathrm{YF}_{\mathrm{S}} \mathrm{SF}$, and $\mathrm{PF}$ variants and not significant with the PL variant. The lowest average bulk density value was obtained in soils under the PF variant.

Silva et al. (2010) demonstrated that anthropic action changes the physical properties of the yellow Latosol (yellow ferralitic) soil, finding that the highest bulk density values are presented at a depth of $0-5 \mathrm{~cm}$. Thus, the authors conclude that anthropic action significantly changed the soil-density values, not only on the surface but also at deeper layers. The organic matter of soils and the biological activity of tropical soils exert a significant influence on their physical and chemical properties. Ralisch et al. (2010) determined that in lands prepared with the use of machinery, degradation of soil structure and compaction occur, in contrast to when the ground is prepared with animal traction.

The results obtained confirm that with $\mathrm{CU}$, organic matter is lost, and thus, the soil's carbon content is lost and transformations are manifested that give rise to the degeneration of the soil's physical properties. Currently, there are results of investigations that analyze different soil preparation methods in relation to the behavior of the organic matter, the carbon in the soil, and other properties, such as bulk density, soil structure and compaction (Olson, 2013).

In this study, it is notable that physical properties, such as the dispersion factor and volume density, do not reach higher values for the $\mathrm{CU}$ variant, despite the fact that the soils were subjected to CU for $>50$ years. The bulk density values are not as high as in other soils in other regions. This situation is mainly due to the characteristics of the soil, which has a very clayish texture and a ferralitic composition with a relatively high free-iron content. In these soils, microaggregates are formed by the action of the clay, iron, and organic matter (Cooper et al., 2005). Therefore, the iron maintains a significant content of organic matter bound to the microaggregates, which decomposes only with difficulty.

The content of organic matter, especially in the humus fraction, together with the iron, forms stable microaggregates in the upper part of the profile as part of the natural formation of Ferralsol, Nitisol, and Lixisol soils (Cooper et al., 2005), which tend to diminish due to anthro-tropic influence when soil is subjected to intense cultivation. Deng et al. (2009) highlighted the role of iron in the formation of microaggregates in tropical soils and present results by which the authors demonstrate that in soil with 56 years of sugar cane cultivation, despite the great loss in OC, there is only a small diminution in the macroaggregate fraction.

\section{Conclusions}

Continuous cultivation causes a degradation of OC-stock in the soil profile $(0-100 \mathrm{~cm})$ in lixic ferralic Nitisol soils. Soils under the primary forest $180-100$ years old) have a higher organic carbon sequestration of $153 \mathrm{Mg} \mathrm{ha}^{-1}$, followed by the secondary forest (45-50 years old) with $143 \mathrm{Mg} \mathrm{ha}^{-1}$, then the young forest (1525 years old) with $124 \mathrm{Mg} \mathrm{ha}^{-1}$, the soils under pasture with $123 \mathrm{Mg} \mathrm{ha}^{-1}$, and lastly, the soils under continuous cultivation with $78 \mathrm{Mg} \mathrm{ha}^{-1}$.

Carbon loss leads to degradation of the physical properties in these soils, such as the soil dispersion factor and volume density. Despite these negative impacts on these soils' properties, an aggregation level is maintained due to the soils' iron and clay content.

\section{References}

Angers, D.A.; Arrouays, D.; Saby, N.P.A.; Walter, C. 2011. Estimating and mapping the carbon saturation deficit of French agricultural topsoils. Soil Use and Management 27: 448-452.

Batjes, N.H. 1996. Total carbon and nitrogen in the soils of the world. European Journal of Soil Science 47: 151-163.

Batjes, N.H. 2008. Mapping soil carbon stocks of Central Africa using SOTER. Geoderma 146: 58-65.

Batlle-Bayer, L.; Batjes, N.H.; Bindraban, P.S. 2010. Changes in organic carbon stocks upon land use conversion in the Brazilian Cerrado: a review. Agriculture, Ecosystems and Environment 137: 47-58.

Beare, M.H.; Hu, S.; Coleman, D.C.; Hendrix, P.F. 2007. Influences of mycelial fungi on soil aggregation and organic matter storage in conventional and no-tillage soils. Applied Soil Ecology 5: 211-219.

Bedini, S.; Pellegrino, E.; Avio, L.; Pellegrini, S.; Bazzoffi, P.; Argese, E.; Giovannetti, M. 2009. Changes in soil aggregation and glomalin-related soil protein content as affected by the arbuscular mycorrizal fungal species Glomus mosseae and Glomus intraradices. Soil Biology \& Biochemistry 41:14911496.

Carrizo, M.E.; Alesso, C.A.; Cosentino, D.; Imhoff, S. 2015. Aggregation agents and structural stability in soils with different texture and organic carbon contents. Scientia Agricola 72: 75-82.

Cheng, H.; Bai, R.; Li, K.; Zhao, C. 2011. Study of loss or gain of soil organic carbon in Da'an region, Jilin Province in China. Journal of Geochemical Exploration 112: 272-275.

Cooper, M.; Vidal Torrado, P.; Chaplot, V. 2005. Origin of microaggregates in soils with ferralic horizons. Scientia Agricola 62: 256-263.

Deng, W.; Wu, D.; Wang, H.; Luo, W.; Kimberley, M.O. 2009. Temporal dynamics of iron-rich, tropical soil organic carbon pools after land-use change from forest to sugar cane. Journal of Soil and Sediments 9: 112-120.

Don, A.; Schumacher, J.; Beltrami, H. 2011. Impact of tropical land use change on soil organic carbon stocks- a meta-analysis. Global Change Biology 17: 1658-1670. 
Fonseca, W.; Rey, J.M.; Alice, F.E. 2011. Carbon accumulation in the biomass and soil of different aged secondary forests in the humid tropics of Costa Rica. Forest Ecology and Management 262: 1400-1408.

Grand, S.; Lavkulich, L.M. 2011. Depth distribution and predictors of soil organic carbon in Podsols of a forested watershed in Southwestern Canada. Soil Science 176:164-174.

Green, V.S.; Stott, D.E.; Cruz, J.C.; Kuri, N. 2007. Tillage impacts on soil biological activity and aggregation in a Brazilian Cerrado Oxisol. Soil \& Tillage Research 92: 114-121.

Hernández, A.; Morales, M.; Ascanio, M.O.; Borges, Y.; Vargas, D.; Bernal, A. 2013. Degradation of red ferralitic lixiviated soils and indicators of the Red Valley Havanna. Cultivos Tropicales 34: 45-51 (in Spanish, with abstract in English).

Hevia, G.G.; Méndez, M.; Buschiazzo D.E. 2007. Tillage affects soil aggregation parameters linked with wind erosion. Geoderma 140: 90-96.

Hunke, P.; Roller, R.; Zeilhofer, P.; Schroder, B.; Mueller, E.N. 2014. Soil changes under different land-uses in the Cerrado of Mato Grosso, Brazil. Geoderma Regional 4: 31-43.

Intergovernmental Panel on Climate Change [IPCC]. 2007. Synthesis Report. Contribution of Working Groups I, II \& III to the $4^{\text {th }}$ Assessment Report of the Intergovernmental Panel on Climate Change. IPCC, Geneva, Switzerland.

International Union of Soil Sciences [IUSS]. 2014. World Reference Base for Soil Resources 2014: International Soil Classification System for Naming Soils and Creating Legends for Soil Maps. FAO, Rome, Italy. (World Soil Resources Reports, 106).

Lal, R.; Follet, R.; Stewart, B.A.; Kimble, J.M. 2007. Soil carbon sequestration to mitigate climate change and advance food security. Soil Science 172: 943-956.

Morisada, K.; Ono, K.; Kanomata, H. 2003. Organic carbon stock in forest soils in Japan. Geoderma 119: 21-32.

Noellmeyer, E.R. 2008. Carbon content and aggregation related to soil physical and biological properties under a land-use sequence in the semiarid region of Central Argentina. Soil \& Tillage Research 99: 179-190.

Olson, K.R.; Al-Kaisi, M.M. 2015. The importance of soil sampling depth for accurate account of soil organic carbon sequestration, storage, retention and loss. Catena 125: 33-37.
Olson, K.R.; Gennadiyev, A.N.; Kovach, R.G.; Shumacher, T.E. 2014. Comparison of prairie and eroded agricultural lands on soil organic carbon retention (South Dakota). Open Journal of Soil Science: 4: 136-150.

Olson, K.R.; Gennadiyev, A.N.; Zhidkin, A.P.; Markelov, M.V. 2011. Impact of land use change and soil erosion in upper Mississippi River Valley on soil organic carbon retention and greenhouse gas emissions. Soil Science: 176: 449-458.

Olson, K.R.; Gennadiyev, A.N.; Zhidkin, A.P.; Markelov, M.V. 2012. Impacts of land-use change, slope, and erosion on soil organic carbon retention and storage. Soil Science: 177: 269278.

Olson, K.R. 2013. Soil organic carbon sequestration, storage, retention and loss in U.S. croplands: issues paper for protocol development. Geoderma 195-196: 201-206.

Padmanabhan E.; Eswaran, H.; Reich, P.F. 2013. Soil carbon stocks in Sarawak, Malaysia. Science of the Total Environment 465: 196-204.

Ralisch, R.; Almeida, E.; Silva, A.P.; Pereira Neto, O.C.; Guimarães, M.F. 2010. Morphostructural characterization of soil conventionally tilled with mechanized and animal traction with and without cover crop. Revista Brasileira de Ciência do Solo 34: 1795-1802.

Silva, F.; Cavalcante, A.A.; Carvalho, L.F.; Menezes, Z.; Sousa, A.C.M. 2010. Physical quality of a yellow Latosol under integrated crop-livestock. Revista Brasileira de Ciência do Solo 34: 717-723.

Telles, E.C.C.; Camargo, P.B.; Martinelli, L.A.; Trumbore, S.E.; Costa, E.S.; Santos, J.; Higucchi, N.; Oliveira, R.C. 2003. Influence of soil texture on carbon dynamics and storage potential in tropical forest soils of Amazonia. Global Biogeochemical Cycles 17: 1040-1052.

Xiong, X.; Grunwald, S.; Myers, B.D.; Ross, C.W.; Harris, W.G.; Comerford, N.B. 2014. Interaction effects of climate and land use/land cover change on soil organic sequestration. Science of the Total Environment 493: 974-982. 